\title{
Design of a Broadband Inverted Conical Quadrifilar Helix Antenna
}

\author{
Jingyan Mo, ${ }^{1,2}$ Wei Liu, ${ }^{3}$ Weidong Fang, ${ }^{1}$ Haigao Xue, ${ }^{1}$ and Zhongchao Lin ${ }^{4}$ \\ ${ }^{1}$ School of Communication and Information Engineering, Shanghai University, Shanghai 200444, China \\ ${ }^{2}$ Shanghai Institute of Aerospace System Engineering, Shanghai 200108, China \\ ${ }^{3}$ Shanghai Satellite Engineering Institute, Shanghai 200240, China \\ ${ }^{4}$ School of Electronic Engineering, Xidian University, Xi'an, Shanxi 710071, China \\ Correspondence should be addressed to Jingyan Mo; mojingyan@163.com
}

Received 17 November 2015; Revised 8 January 2016; Accepted 11 January 2016

Academic Editor: Ikmo Park

Copyright (c) 2016 Jingyan Mo et al. This is an open access article distributed under the Creative Commons Attribution License, which permits unrestricted use, distribution, and reproduction in any medium, provided the original work is properly cited.

\begin{abstract}
This paper introduces the design of a broadband inverted conical circularly polarized quadrifilar helix antenna (QHA). The antenna has many good characteristics, including wide beam and broad bandwidth, which are achieved by utilizing inverted conical geometry and adjusting the dimensions of the inverted conical support. The antenna is fed by a wideband network to provide $90^{\circ}$ phase difference between the four arms with constant amplitude. The antenna impedance and axial ratio bandwidth values are more than $39 \%$ and $31.5 \%$, respectively. The measured results coincide well with the simulated ones, which verified the effectiveness of the proposed design.
\end{abstract}

\section{Introduction}

With the rapid development of GPS and SNS, antenna plays a more crucial role on the system performance. Moreover, cardioid-shaped radiation patterns with good circular polarization in a broad bandwidth are required tremendously for satellite communication and navigation systems [1].

Quadrifilar helix antenna (QHA), because of its small size, cardioid-shaped radiation pattern, and excellent circular polarization over a wide angular range, is a promising candidate for the GPS and SNS applications [2]. Nevertheless, the bandwidth of a conventional QHA operating under resonant modes is generally not very wide, which constrains its application. The bandwidth of a printed QHA is typically equal to 5 to $8 \%$, and by using a variable arm width to obtain the tapered printed QHA its bandwidth can be increased to about 15\% [3]. In recent years, several other techniques have been described in the literature to broaden the bandwidth of the QHA. In the literature [4], by introducing the conical helix geometry, an $18.5 \%$ bandwidth can be achieved. When the conical geometry and the tapering helices are combined, the antenna bandwidth reaches to more than 25\% [5]. In the literature [6], a technique by adding a shorted parasitic helix is presented, and the folded printed QHA obtains 30\% of impedance bandwidth in axial mode. Besides, there are also many techniques proposed for one QHA to cover the multiband [7-11].

In this document, the printed quadrifilar helical arms are wrapped in an inverted conical shape, called inverted conical printed quadrifilar helical antenna (ICPQHA), and are integrated directly above the ground plane of the feed network. By adjusting the dimensions of the inverted cone, the equivalent impedance of the antenna will be changed and matched, and the bandwidth of the proposed antenna is more than $39 \%$. The theoretical and experimental results also have reasonably good agreements.

The reminder of this letter is organized as follows: Section 2 presents the antenna structure and design. Section 3 discusses the simulated and measured results, including bandwidth, radiation pattern, and circularly polarized ratio. Section 4 gives the conclusions.

\section{Antenna Structure}

A typical QHA consists of four helices equally spaced and excited with sequential phase variation, $0^{\circ}, 90^{\circ}, 180^{\circ}$, and 


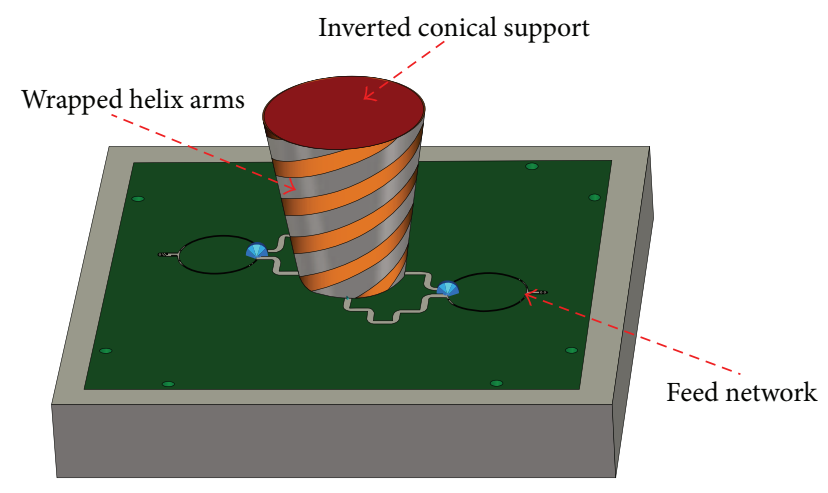

FIGURE 1: The holistic configuration of the QHA.

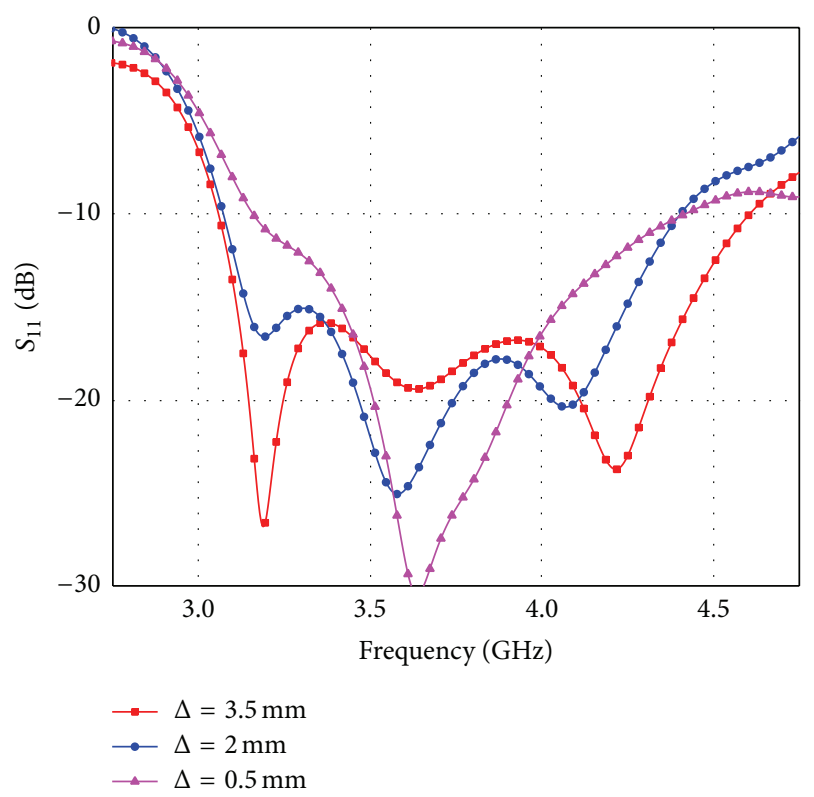

Figure 2: Effect of parameter $\Delta$ on antenna $\left|S_{11}\right|$.

$270^{\circ}$. In our work, an inverted conical geometry is introduced to enhance the bandwidth of the antenna, and this inverted conical geometry with the underneath ground is inspired by the discone antenna which shows characteristics of ultrawideband [12]. The antenna is designed to operate in lefthand circular polarization (LHCP). The procedure for the antenna design can be divided into three steps. The first step is to design the radiating structure of the ICPQHA with four coaxial inputs. The second step is to design the feed network. The final step is to integrate the radiating structure with the feed network to form the complete model.

2.1. Antenna Configuration. Figure 1 shows the configuration of the proposed ICPQHA with its integrated-feed network underneath, operating at the center frequency of $3.85 \mathrm{GHz}$. The four helix-shaped radiating elements are printed onto a thin dielectric substrate of relative permittivity $\varepsilon_{r}=2.94$ and of thickness $h=0.254 \mathrm{~mm}$, wrapped around an inverted conical support made of cork wood and mounted on a small ground plane of the feed network. A square metal frame is set

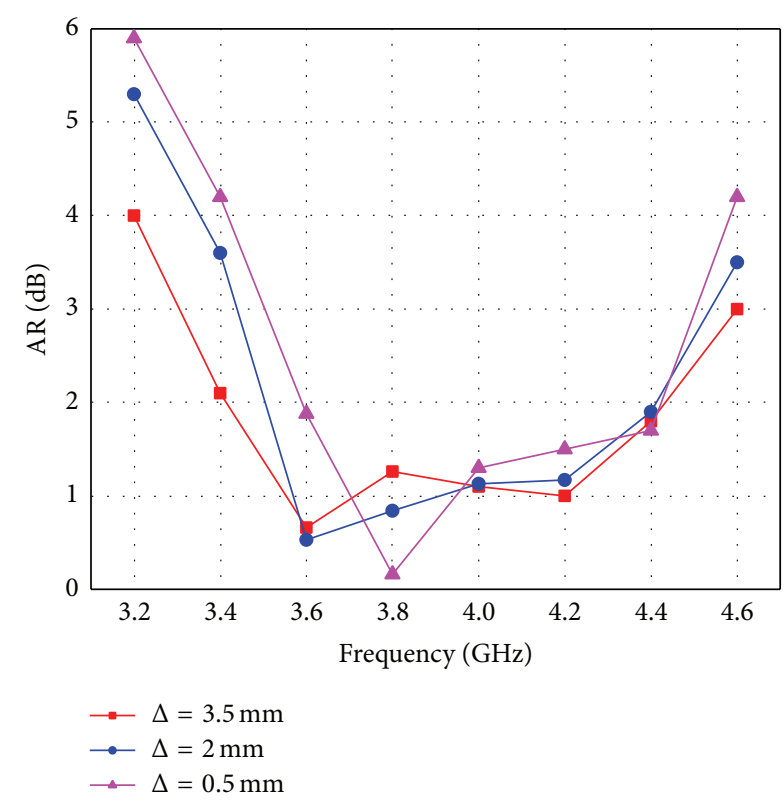

FIgURE 3: Effect of parameter $\Delta$ on antenna AR.

around the substrate for mounting and withstanding physical abuse, whose edge length is $W_{g}=70 \mathrm{~mm}$.

The drawing function for generating the inverted conical helical arms is using the following parameters of the inverted conical helix: the initial radius $r_{0}$, pitch distance $d_{p}$, number of turns $N$, radius change per-turn $\Delta$, and the arm width $W$. One of the helical arms, starting from $+x$ axis in the $x-o-y$ plane, can be described by the following equations:

$$
\begin{aligned}
& x=\left(r_{0}+\Delta \frac{\theta}{2 \pi}\right) \cdot \cos \theta, \\
& y=\left(r_{0}+\Delta \frac{\theta}{2 \pi}\right) \cdot \sin \theta, \\
& z=\frac{\theta}{2 \pi} d_{p},
\end{aligned}
$$

$$
0 \leq \theta \leq 2 N \pi
$$

The geometrical parameters of the final antenna are listed in Table 1.

Figures 2 and 3 show the effect of radius change perturn $\Delta$ on the antenna performance. When $\Delta$ changes from positive to zero, negative, the antenna geometry changes from inverted cone to cylinder and cone, gradually. As $\Delta$ decreases from $3.5 \mathrm{~mm}$ to $0.5 \mathrm{~mm}$, the $\left|S_{11}\right|$ as well as axial ratio (AR) performance is worse gradually, which shows that the inverted conical geometry has better performance and verifies the effectiveness of our design.

Impacts of the ground size on antenna radiation are also studied and shown in Figure 4. When the ground edge length $W_{g}$ increase from $70 \mathrm{~mm}$ to $90 \mathrm{~mm}$, the antenna radiation has little variation and shows high stability.

2.2. Feed Network Configuration. The feeding network plays a critical role on ensuring the antenna's performance. To excite 


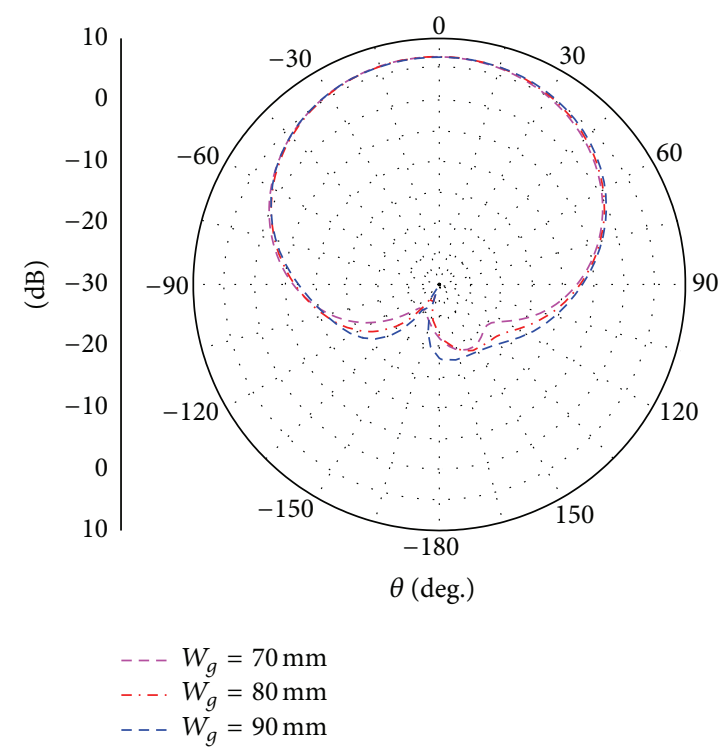

FIGURE 4: Impact of the ground size on antenna radiation.

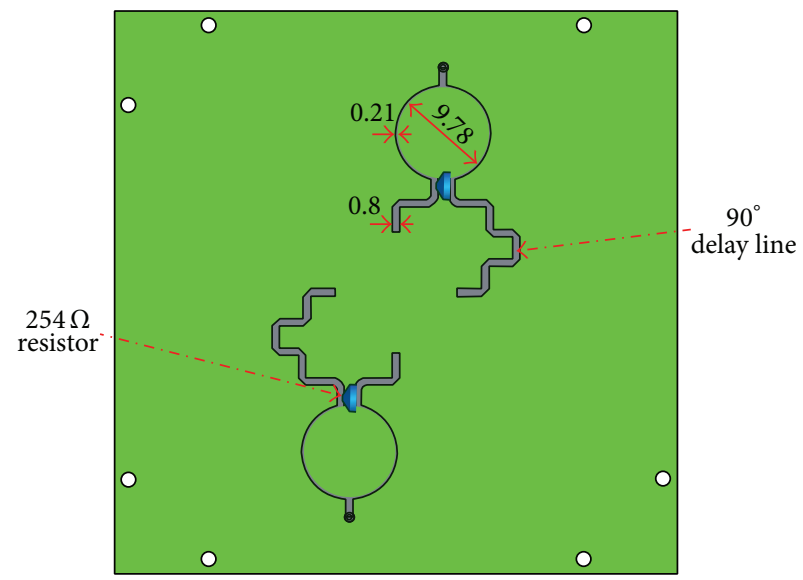

(a)

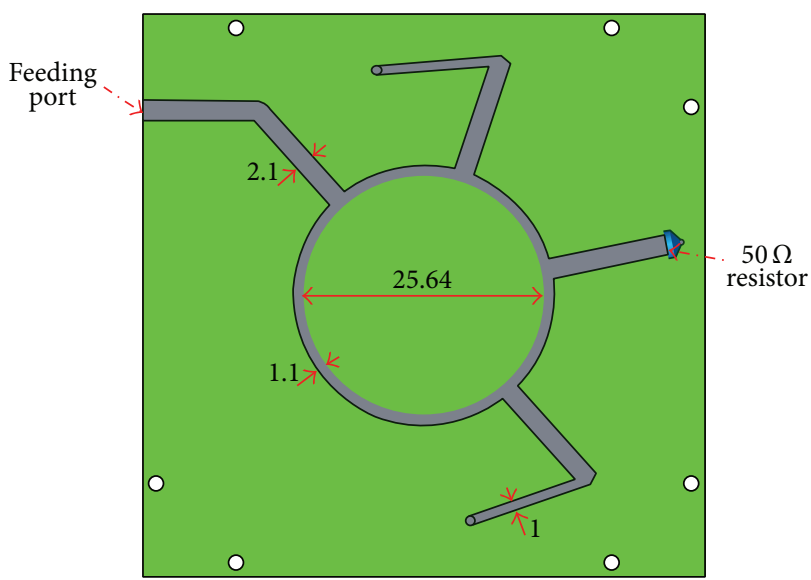

(b)

FIGURE 5: Geometry of the feed network (item: $\mathrm{mm}$ ). (a) Downward view of the upper substrate, (b) bottom view of the lower substrate.

TABLE 1: The geometrical parameters of the final antenna.

\begin{tabular}{lc}
\hline$r_{0}$ & $10.1 \mathrm{~mm}$ \\
$d_{p}$ & $21.8 \mathrm{~mm}$ \\
$N$ & 1 \\
$W$ & $3 \mathrm{~mm}$ \\
$\Delta$ & $3.5 \mathrm{~mm}$ \\
$W_{g}$ & $70 \mathrm{~mm}$ \\
\hline
\end{tabular}

the four arms with constant amplitude as well as quadrant phase difference throughout the whole bandwidth, we design a wideband feed network in a shunt-fed format and use one $180^{\circ}$ ring hybrid and two Wilkinson dividers to satisfy the requirement. The network is composed of two substrate layers with a ground plane in the middle. The $180^{\circ}$ ring hybrid is printed on the lower surface of the bottom substrate layer, and the Wilkinson dividers are printed on the top surface of the upper substrate layer. The bottom and top layer of the network are connected with shorting pins. Figure 5 gives the geometry of the designed feed network. The designed feed network is centered at $3.85 \mathrm{GHz}$ and uses the substrates with the permittivity of 2.55 and the thickness of $2 \mathrm{~mm}$ and $0.762 \mathrm{~mm}$, respectively. And the top substrate is thicker because it also serves as a base for the inverted conical support made of cork wood.

Simulated magnitude response and phase differences of the feed network are shown in Figure 6. It is observed that the maximum difference of magnitude is within $0.2 \mathrm{~dB}$ in the band of 3 to $4.6 \mathrm{GHz}$. The simulated phase differences of the other three output ports, with respect to Port 2, are with sequential phase variation, $90^{\circ}, 180^{\circ}$, and $270^{\circ}$. 


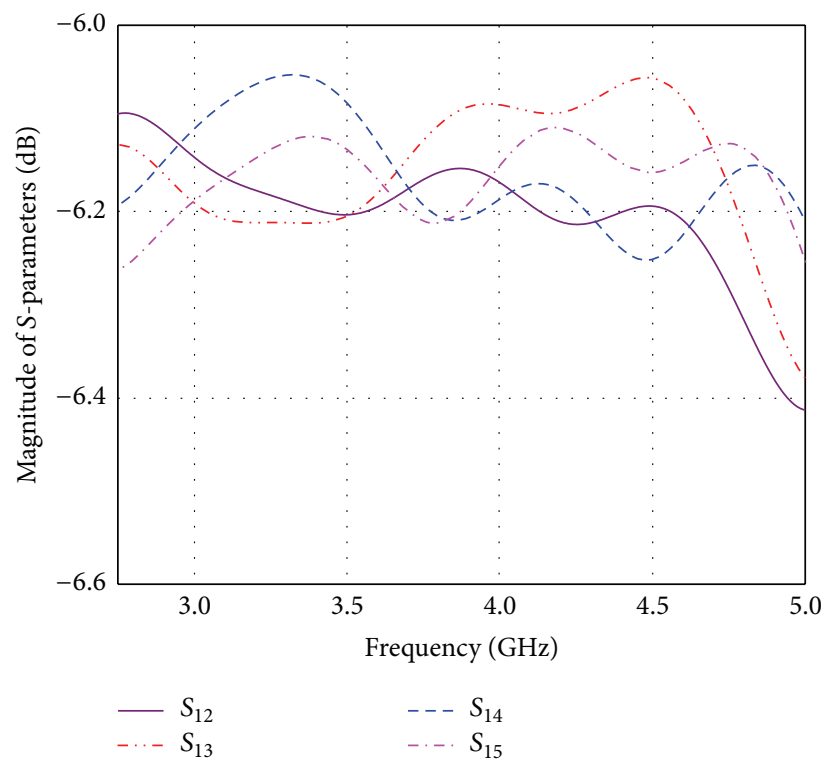

(a)

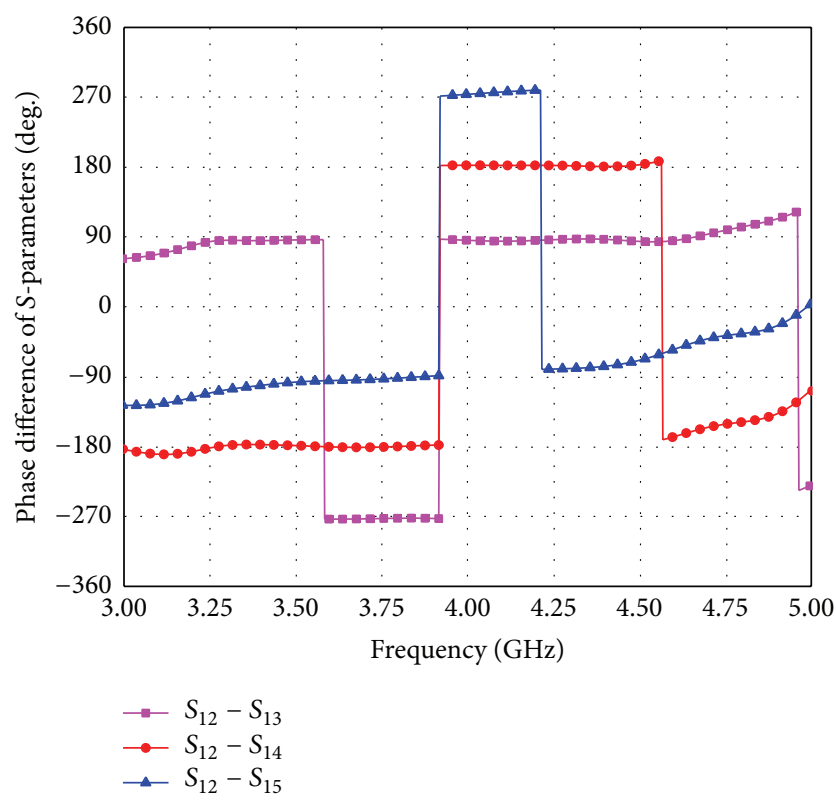

(b)

FIgURE 6: Simulated S-parameters of the designed feed network. (a) Magnitude and (b) phase difference.

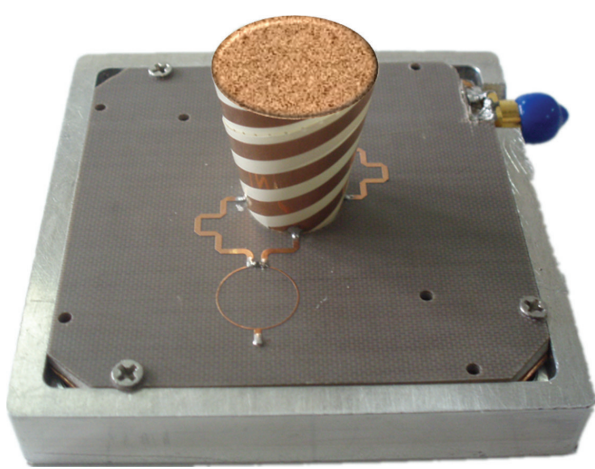

(a)

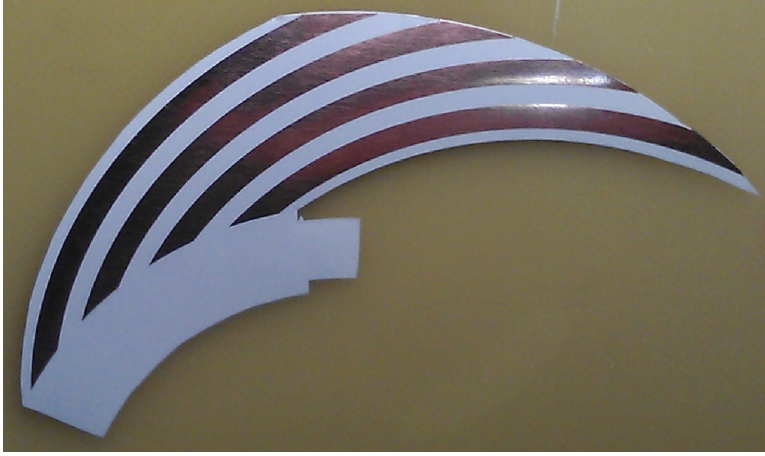

(b)

FIGURE 7: Fabricated prototype of the test antenna. (a) Integral structure. (b) Unwrapped helix arm.

\section{Results and Discussion}

The design works of the proposed ICPQHA are carried out with CST Microwave Studio software based on the finite integration technique (FIT) method. To verify the proposed antenna design, the prototype antenna was fabricated, as shown in Figure 7.

The measurement of $S$-parameter was carried out with vector network analyzer Agilent 8722ES, and the simulated and measured $\left|S_{11}\right|$ of the ICPQHA are shown in Figure 8 for comparisons. Good agreement between the simulated and measured results is observed, where the test antenna achieves an impedance bandwidth of over $39 \%$ for $\left|S_{11}\right|<-10 \mathrm{~dB}$, covering the frequency range from $3.1 \mathrm{GHz}$ to $4.6 \mathrm{GHz}$.

The radiation patterns of the ICPQHA were measured in the far-field anechoic chamber. The simulated and measured radiation patterns at $\varphi=0^{\circ}$ for $3.6 \mathrm{GHz}$ and $4.4 \mathrm{GHz}$ are depicted in Figure 9, which coincide with each other, especially for the copolarizations. And the polarization isolation of LHCP and RHCP is more than $20 \mathrm{~dB}$. The measured and simulated AR patterns at $\varphi=0^{\circ}$ for $3.6 \mathrm{GHz}$ and $4.4 \mathrm{GHz}$ are also plotted in Figure 10. It is observed that, though there is some discrepancy between the measured and simulated results due to the machining error, the $A R$ is still below $3 \mathrm{~dB}$ when $\theta$ varies from $-60^{\circ}$ to $70^{\circ}$, showing that the antenna has a wide angular coverage, since the corresponding angular coverage for a typical microstrip antenna is only about $\pm 50^{\circ}$ [13].

Figure 11 plots the measured LHCP gain versus frequency. It is seen that a stable gain over $6 \mathrm{dBic}$ is obtained from 3.2 $\mathrm{GHz}$ to $4.4 \mathrm{GHz}$ and a little decrease in the high frequency but still over $5.4 \mathrm{dBic}$. The measured AR versus frequency 


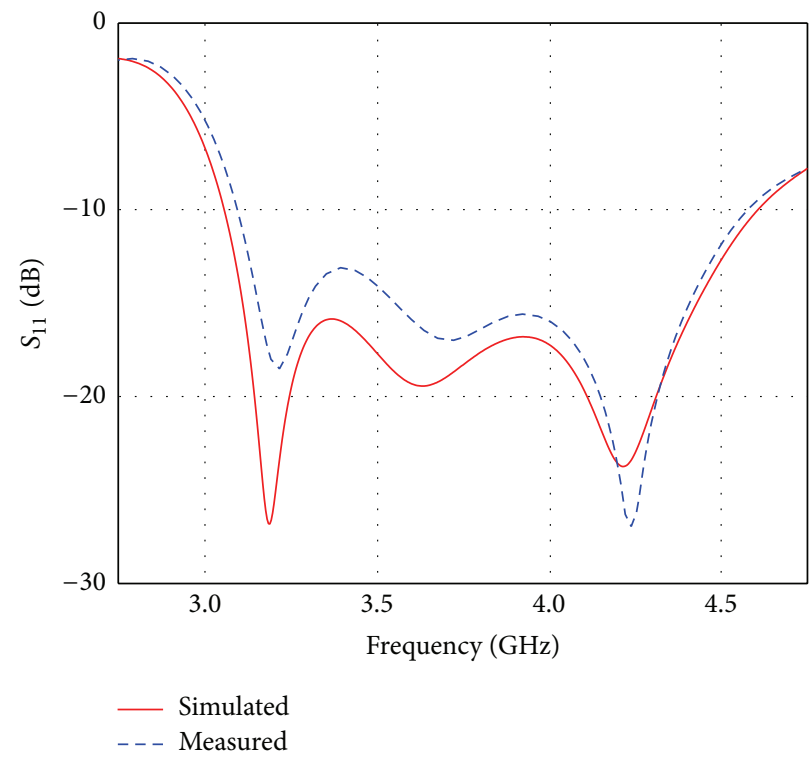

Figure 8: Measured and simulated $\left|S_{11}\right|$.

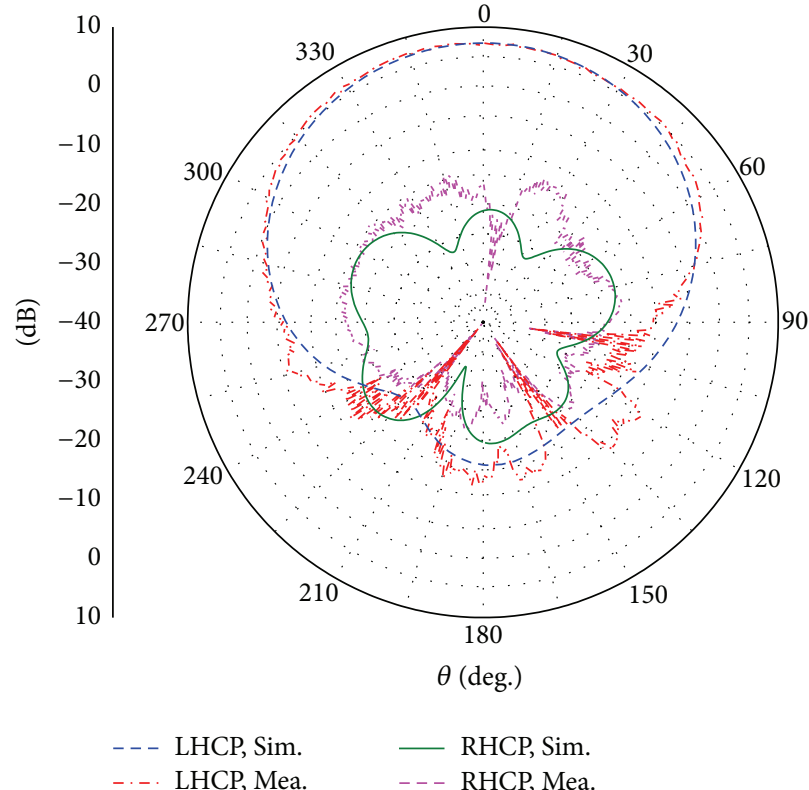

(a)

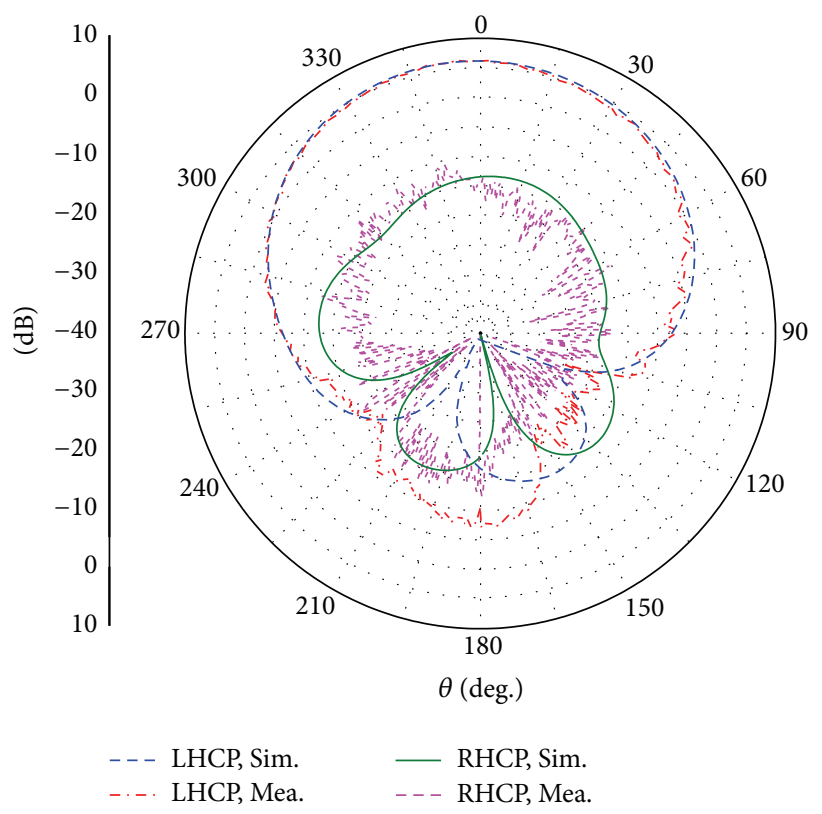

(b)

FIGURE 9: Measured and simulated radiation patterns. (a) $3.6 \mathrm{GHz}$ and (b) $4.4 \mathrm{GHz}$.

is shown in Figure 12, where the ICPQHA has an effective $3 \mathrm{~dB}$ axial ratio bandwidth of greater than $31.5 \%$, ranging from $3.35 \mathrm{GHz}$ to $4.6 \mathrm{GHz}$.

\section{Conclusion}

In summary, a circularly polarized printed quadrifilar helix antenna with much wider frequency bandwidth is presented. The printed helical arms are wrapped in an inverted conical shape and a wideband feed network is integrated directly to excite high-performance LHCP radiation. The antenna impedance and axial ratio bandwidth values are more than $39 \%$ and $31.5 \%$, respectively, which make the proposed antenna a promising candidate for satellite communication and navigation systems.

\section{Conflict of Interests}

The authors declare that there is no conflict of interests regarding the publication of this paper. 

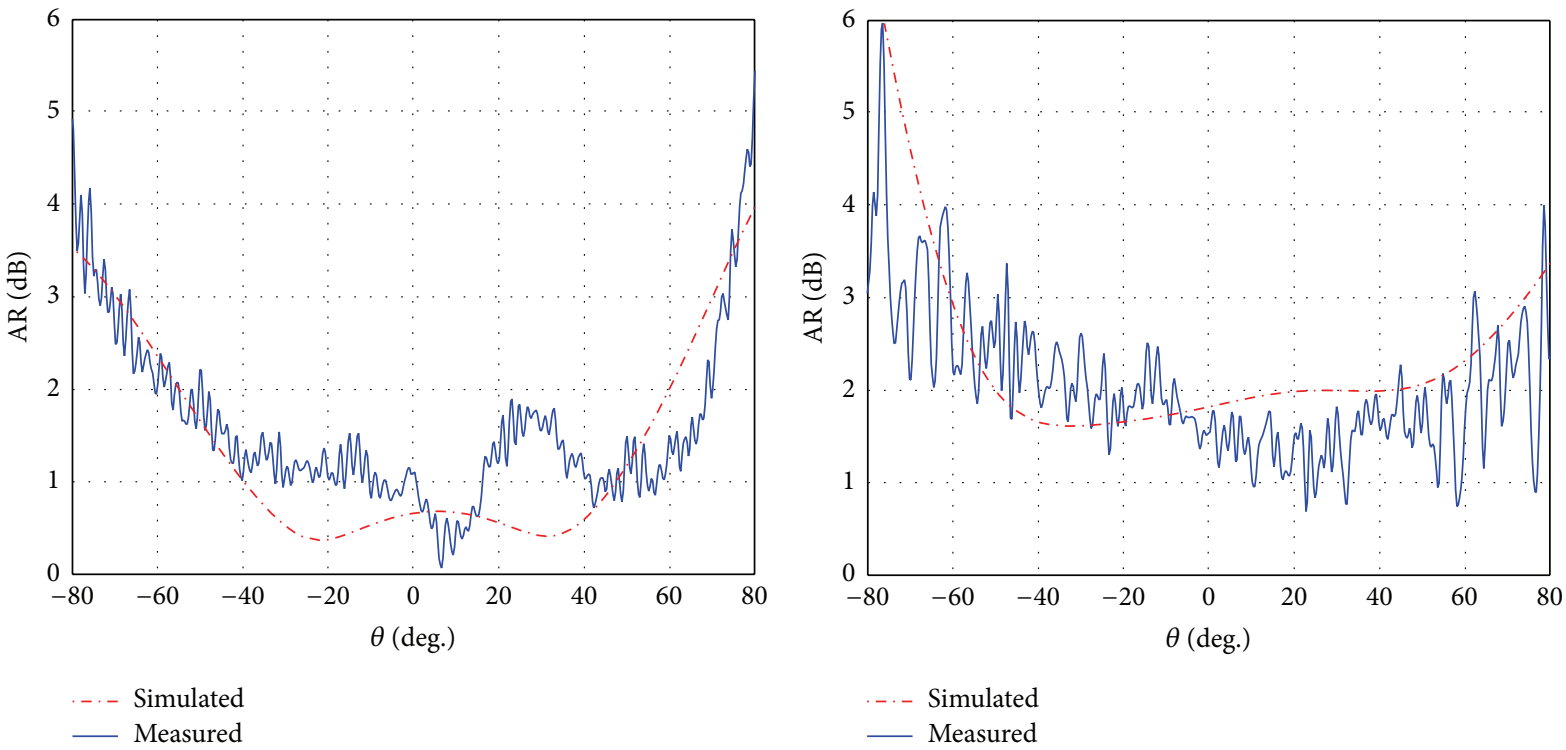

(a)

(b)

Figure 10: Measured and simulated AR. (a) $3.6 \mathrm{GHz}$ and (b) $4.4 \mathrm{GHz}$.

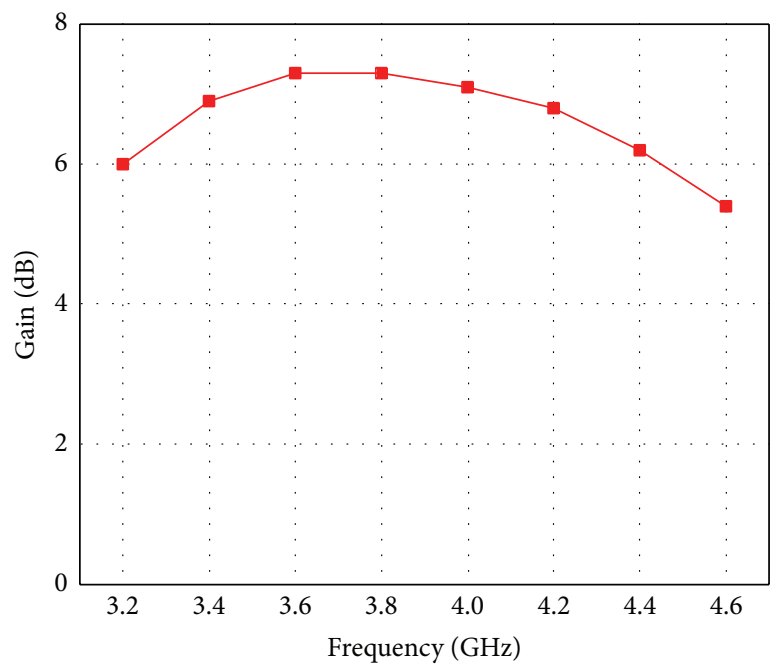

Figure 11: Measured LHCP gain versus frequency.

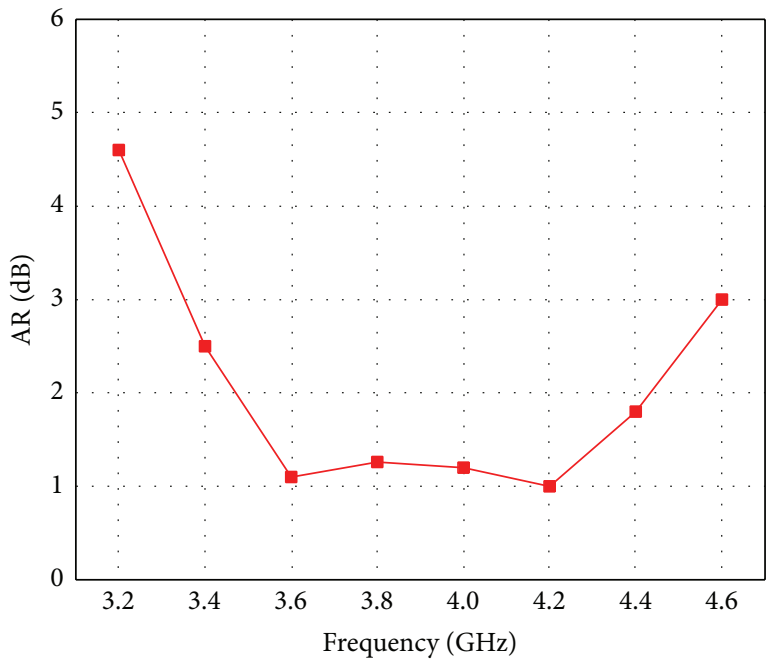

FIGURE 12: Measured AR versus frequency. 


\section{Acknowledgment}

This work was supported by the National Natural Science Foundation under Grant 61401447.

\section{References}

[1] J. M. Tranquilla and S. R. Best, "A study of the quadrifilar helix antenna for Global Positioning System (GPS) applications," IEEE Transactions on Antennas and Propagation, vol. 38, no. 10, pp. 1545-1550, 1990.

[2] C. C. Kilgus, "Shaped-conical radiation pattern performance of the backfire quadrifilar helix," IEEE Transactions on Antennas and Propagation, vol. 23, no. 3, pp. 392-397, 1975.

[3] J. C. Louvigné and A. Sharaiha, "Broadband tapered printed quadrifilar helical antenna," Electronics Letters, vol. 37, no. 15, pp. 932-933, 2001.

[4] S. Yang, S. H. Tan, Y. B. Gan, and C. W. See, "Broadband conical printed quadrifilar helical antenna with integrated feed network," Microwave and Optical Technology Letters, vol. 35, no. 6, pp. 491-493, 2002.

[5] B. Ning, J. Lei, Y. Cao, and L. Dong, "A conical quadrifilar helix antenna for GNSS applications," in Proceedings of the International Symposium on Antennas \& Propagation (ISAP '13), vol. 1, pp. 543-546, IEEE, Nanjing, China, October 2013.

[6] Y. Letestu and A. Sharaiha, "Broadband folded printed quadrifilar helical antenna," IEEE Transactions on Antennas and Propagation, vol. 54, no. 5, pp. 1600-1604, 2006.

[7] M. Hosseini, M. Hakkak, and P. Rezaei, "Design of a dualband quadrifilar helix antenna," IEEE Antennas and Wireless Propagation Letters, vol. 4, pp. 39-42, 2005.

[8] W. Y. Qin, J. Qiu, and Q. Wang, "A novel multi-frequency quadrifilar helix antenna," in Proceedings of the IEEE International Symposium on Antennas and Propagation Society International Symposium, vol. 1, pp. 467-470, Washington, DC, USA, 2005.

[9] A. Sharaiha and Y. Letestu, "Quadrifilar helical antennas: wideband and multiband behavior for GPS applications," in Proceedings of the 12th International Conference on Electromagnetics in Advanced Applications (ICEAA '10), pp. 620-623, IEEE, Sydney, Australia, September 2010.

[10] X. Bai, D. Yang, J. Tang, J. Geng, R. Jin, and X. Liang, "A novel dual-band circularly-polarized wide-beam quadrifilar helix antenna," in Proceedings of the Joint IEEE International Symposium on Antennas and Propagation and USNC-URSI National Radio Science Meeting (APSURSI '12), pp. 1-2, Chicago, Ill, USA, July 2012.

[11] X. Bai, J. Tang, X. Liang, J. Geng, and R. Jin, "Compact design of triple-band circularly polarized quadrifilar helix antennas," IEEE Antennas and Wireless Propagation Letters, vol. 13, pp. 380-383, 2014.

[12] A. Chen, T. Jiang, Z. Chen, D. Su, W. Wei, and Y. Zhang, "A wideband VHF/UHF discone-based antenna," IEEE Antennas and Wireless Propagation Letters, vol. 10, pp. 450-453, 2011.

[13] L. Chen, T.-L. Zhang, C. Wang, and X.-W. Shi, "Wideband circularly polarized microstrip antenna with wide beamwidth," IEEE Antennas and Wireless Propagation Letters, vol. 13, pp. 1577-1580, 2014. 


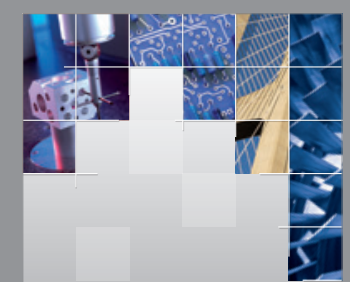

\section{Enfincering}
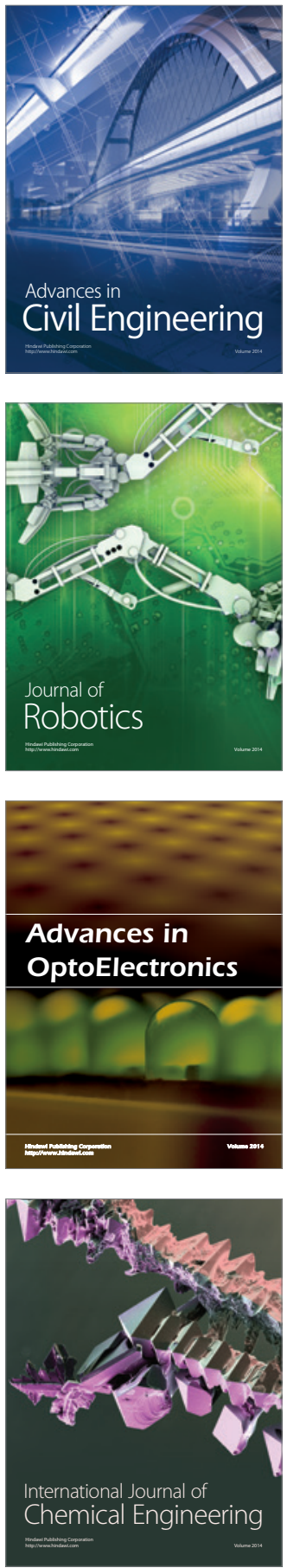

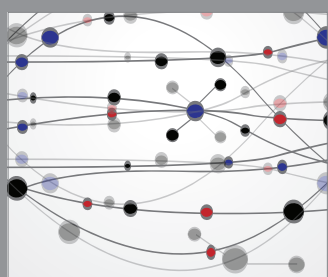

The Scientific World Journal

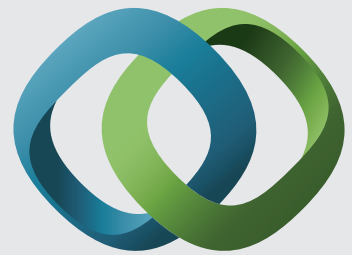

\section{Hindawi}

Submit your manuscripts at

http://www.hindawi.com
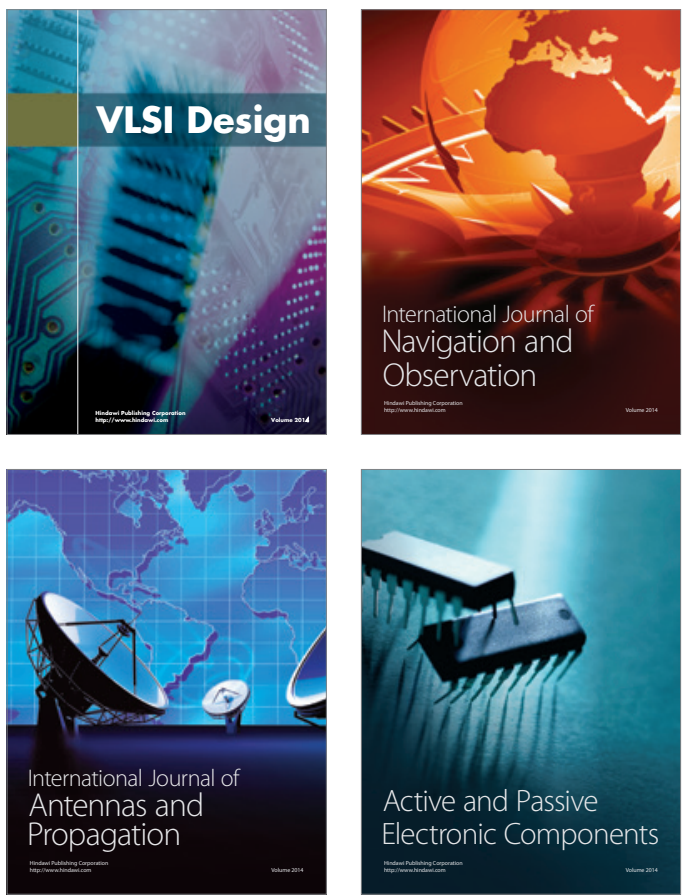
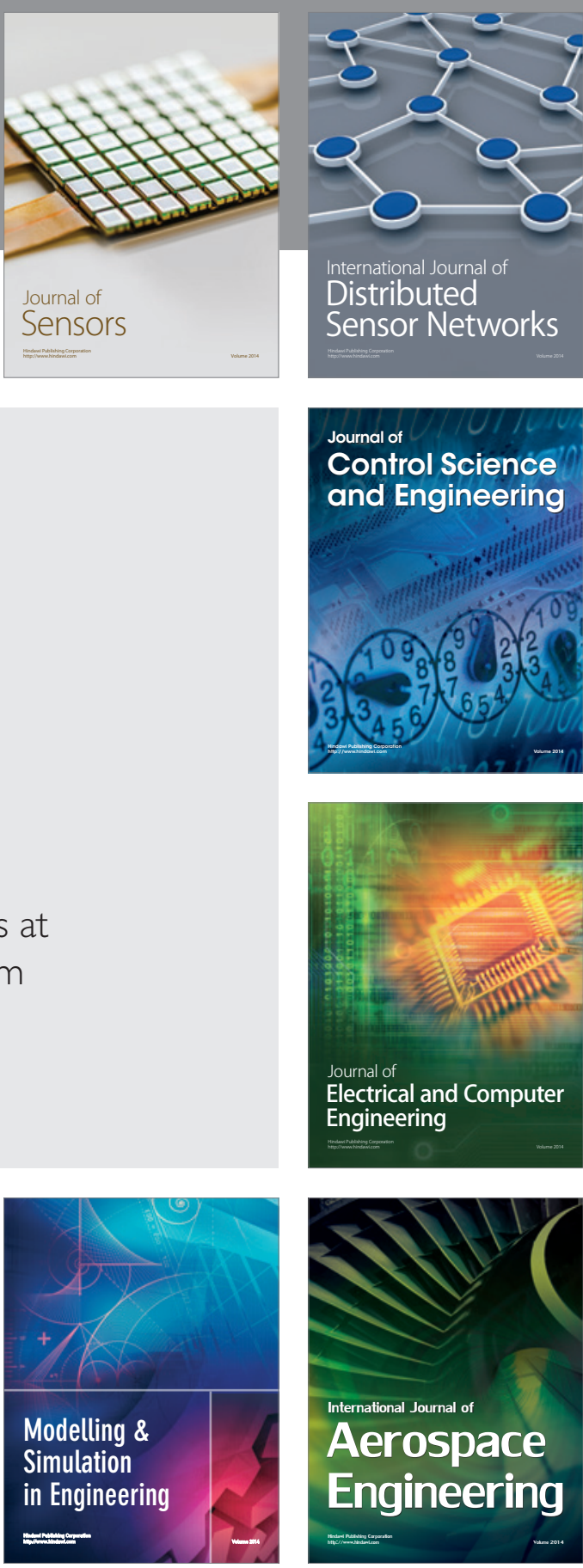

International Journal of

Distributed

Sensor Networks

Journal of

Control Science

and Engineering
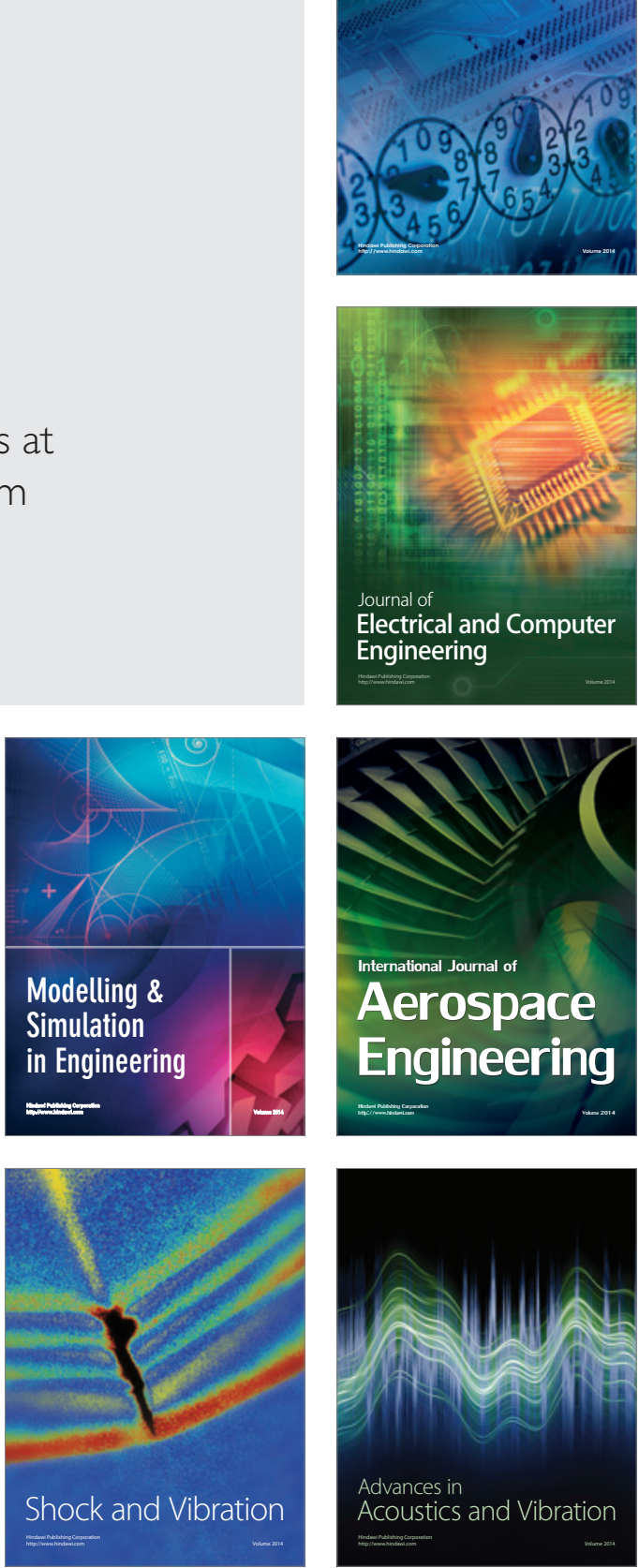